\title{
Die 'godsbegrip van die Afrikaner' met verwysing na Die kreef raak gewoond daaraan van André P. Brink
}

Pieter Verster

Departement Sendingwetenskap

Universiteit van die Oranje-Vrystaat

BLOEMFONTEIN

\begin{abstract}
The Afrikaners' view of God with reference to Die kreef rank gewoond dararan by And ré P. Brink

Die kreef raak geweond dauraun is an importan novel, m which a variety of themes are under convideratom. One of these themes is the Afrikaners' belief in (iod. Thomas, the man character, says that the Afrikaners' belief in God is the foundatum of therr entre way of thinkmg. They believe m a (jod of justice and retaluatom and therefore find it easy to suppress people. It is, homever clear that quite a few arguments against the premises of the man character and the impliced awhor can be propounded.
\end{abstract}

\section{Inleiding}

Die krecf raak ge'woond daaraan (Brink, 1991) is 'n belangrike werk, enersyds op grond van die verskeidenheid van temas wat aangeraak word en andersyds op grond van die omvang en hantering van die verskillende temas. Verskillende kritic se beoordeling van die roman loop uiteen: Reinders (Beeld. 1992-02-18, p. 2) beskou die roman as simplisties en eensydig en Joln Gultig (Natal Wimess, 1992-03-23, p. 7) beskryf die roman as "a flat, one dimensional and dead representation of reality". Daanteenoor beskryf la van $Z y$ l die roman as meesterlik (Republike'm, 1992-04-30, p 5) en Ester (Zund-Afrika, 1992:14) deel hierdie beskouing met die opskrif by sy beoordeling: "Brink op z'n best"

\section{Verwysings na die godsbegrip van die Afrikaner in Die kreef raak gewoond daaraan}

Ten spyte van en in die lig van die konflikterende beskouings oor die roman is daar $\log$ bepaalde temas wat nadere ondersoek verg. Die tema van die godsbegrip van verskillende karakters en die Afrikaner soos beoordeel deur die hoofka- 
rakter is van belang omdat dit 'n spesifieke verband lê tussen die hantering van revolusionêre omstandighede en die godsdiensbeskouing. In hierdie roman word verskeie invalshoeke gebruik om die godsbegrip van verskillende karakters en van die Afrikaner as sodanig van nader te belig.

Die roman handel oor Thomas Landınan, 'n Afrikaner, se verset teen die destydse, sogenaamde apartheidsowerheid. Hy beplan saam met ander 'n bomaanval op die Staatspresident. Hierdie aanval mislık, maar mense sterf. Thomas en die vroulike karakter, Nina, wat ook betrokke was by die aanval, vlug. Vroeg in die roman sterf Nina 'n Ander vroulike karakter, Lisa, wat in opstand is teen haar agtergrond as predikantsdogter, speel later 'n belangrike rol. Brigadier Kat Bester van die Veiligheidspolisie beplan die soektog na die oortreders. Ook Lisa sterf, maar Thomas word wonderbaarlik gered en beleef hoe daar tog verandering kom en hoe die land 'n nuwe toekoms tegemoet gaan

Enkele voorbeelde ten opsigte van die hantering van die godsbegrip word vervolgens van nader bekyk:

Reeds vroeg in die roman neem die vroulike karakter, Nina, standpunt in teen bepaalde beskounge soos gefonnuleer in die Bybel Die Bybelfiguur Judas wek haar simpatie op (vgl. Brink, 1991:4l).' Judas was immers die een wat op soek was na die politieke koninkryk (Kreef:42). Die koninkryk wat Jesus voorhou, is volgens Nina wêreldvreend en dit het geen waarde vir liulle wat ly onder politieke verdrukking nie. Hierdie begrip van God waarin sagmoedigheid as deug beskou is, was wel vroeër deel valn die verhaalfigure se lewe. Hulle lewe het egter intussen verander en hulle het nou 'n ander beskouing: hulle het afskeid geneem van die wêreld waarin God se beskikking aanvaar is - die hier en nou van revolusionêre omstandighede is van belang. Thomas, die hoofkarakter, tree met Nina in gesprek oor die aard van verraad. Hy verduidelik dat hulle daad reg is, ondat dit moreel geregverdig kan word. Nina stel dat Judas dieselfde mening toegedaan was.

Teenoor hierdie twee verhaalfigure staan die broer van Thomas, wat uit 'n heel ander hoek na die werklikheid kyk. Hy neen dat sy revolusionère broer die verdiende loon van sy oortredinge sal ontvang (Kreef:121): hy sal inderdaad in die hel gewerp word. Die godsbegrip wat hier na vore tree, is een van orde, regspraak en veroordeling (Kreef:12l).

Die belangrikste kommentaar kom egter van die loofkarakter self wat die godsdiens en geloofsoortuging van die Afrikaner beoordeel.

1 Brink (1991) venuys na dic roman l)e kreef raak gewoond daaraan - voortaan afgekort as Kreef. 
Hierdie godsdiens is self die fondament van ' $n$ hele staatsorde, 'n manier van dink. Dis waar die fascisme begin. As Adam en Eva kennis kry, word hulle uitgedrywe. God wil nie hè dat hulle self moet kan onderskei tussen goed en kwaad nie. Hy wil vir hulle besluit, hulle in die duister hou. En vroeer al toe die engele gerebelleer het. het Hy hulle kragdadig uit die hemel uitgesmyt. Deur strukturele geweld hou hy sy bestel in stand. Die Afrikaner het maar net sy voorbeeld gevolg. (Kreef: 190.)

Sendelinge het volgens Thomas se beskoung die Nuwe Testament gebruik on mense te leer om onderdrukkmg gelate te aanvaar (Kreef: 190).

Die godsbegrip van die Afrikaner, soos gesien deur die oe van Thomas, is dus vemietigend in die sin dat dit tol Fascisme lei en geen ruimte laat vir die vryheid van die mens voor God nie. Uit die aard van die saak moet erken word dat 'n bepaalde karakter se standpunt nie noodwendig dié van die implisiete outeur of van die werklike outeur is nie. Daar kom egter in 'n bepaalde roman tendense na vore wat 'n bepaalde standpunt rugsteun wat ten minste die standpunt van die implisiete outeur weergee. lierdie tendens is duidelik waarneembaar in Die kreef rack geworsmd disurain.

In die roman word afskeid geneem van die metafisiese wêreldbegrip. Wanneer die wêreld van Dostojewski bespreek word, is dit ook 'n werreld van God en engele en geeste. Ook is daar sprake van skuld en boete (K'reef:427). Die metafisiese wêreld het egter oorgegaan in 'n sostale bestel. Lisa, die ander vroulike hootkarakter, meen dat dit al is wat verder van belang is.

Lisa se predikant-pa word angewend on die tema van die onbannlianigheid van God verder te voer en te illustreer. Thomas en Lisa besoek Lisa se pa terwyl hulle op vlug is. In 'n gesprek met hom verwyt Lisa haar pa dat onreg, geweld en moord gepleeg word in die naam van die kerk en God waarvoor hy hom as predikant afsloof (Kreef 470) Die dommee egter glo aan die straf van God (Kreef: 448). Hy lees voor van die Allerhoogste wat waak oor die lewe (Kreef 448). Wanneer Thomas en lisa intiem verkeer in die kamer, skuifel die predikant rond in die huis en verteenwoordig hy 'n hele bestel van reg en verkeerd, God en sonde, hemel en hel (Kre(149). Hier kom die implisiete outeur aan die woord on die godsbegrip van die predikant te beoordeel. Die predikant aanvaar deemoedig God se beskikking, hy wag op dit wal God gee en leer, hy meen dat toeval me by God bestaan me (Krecet:467). Ook vrees hy die straf van God, omdat hy van mening is dat hy sy ongebore kind 'vennoor' het: hy het naamlik bestuur, die motor se band het gebars en sy vrou is dood. Hy verwyt homself dat hy aan God getwyfel het en onverskillig was toe die motor se band gebars het. Hy verwag egter steeds die oordeel van God (K'reet 468). Hy het God dus met vrees gedien op grond van die moontliklieid dat God tog wel bestaan Wanneer sy dogter die Sondagaand by hom kom en sè dat hy genoeg gewerk het en dat die 
Here seker tevrede is, wil hy antwoord dat die Here nooit tevrede is nie (Kreef:469).

Die predikant glo dat daar in die Bybel duidelik geëis word dat aan die keiser betaal moet word wat hom toekom (Kreef:470). Na 'n telefoongesprek met sy seun stuur hy sy dogter en haar vriend weg van sy huis af. Hy beskou sy eie optrede as deel van die beproewinge wat God oor hom bring

Die tradisionele godsdiens word dus deur die implisiete outeur uitgebeeld aan die hand van die ervaringe van die predikant. Die ervaring van die predikant impliseer dat dit inderdaad vreugdeloos is om God te dien, want Hy is die onbannhartige God. Die vader self tree onbarmhartig op deur sy kind weg te stuur. Brink se karakter worstel egter self met sy interpretasie van die godsbegrip; daarom moet gewaak word teen 'n eensydige beoordeling.

Om die onderliggende gedagtegang in die roman enigsins verder te ontleed is dit belangrik om enkele sake te benadruk Daar is nie 'n eenduidige godsbegrip af te lei uit die verskillende stemme wat na vore kom in die roman nic. In die geheel kom daar egter tog 'n bepaalde tendens na vore wat aandag verdien.

- Daar is verset teen die God van die Bybel - vergelyk Thomas se standpunt dat God strukture in stand hou deur gebruik te maak van strukturele geweld.

- Hierdie God is die God van onreg - die God wat sy eie bestel hoër ag as die heil van mense en mense gevolglik verdnuk op ontstellende wyse

- Hierdie godsbegrip maak dit vir mense moontlik on strukturele geweld te regverdig en on op grond van die optrede van God ook so op te tree.

Die romangegewe bied implisiet kritiek op die godsbegrip van die Afrikaner. Hiervolgens het die Afrikaner van God self die onderdrukker gemaak. (Vergelyk in dié verband die rol van die predikant en die beskrywing deur die implisiete outeur.) Ook kom die volgende aspekte in die roman na vore:

- Die Afrikaner (van 'n gereformeerde kerkgroep?) beleef godsdiens as neerdrukkend

- Die Afrikaner volg die model na wat hy uit die Bybel aflei en dit is die model van absolute gesag wat gelıandhaaf moet word.

Hiermee word nie gesê dat hierdie godsbegrip van die Afrikaner, soos uitgebeeld deur die roman, eenduidig op alle Afrikaners van. toepassing gemaak word nie. Deur middel van die implisiete outeur word egter ernstige vraagtekens agter die godsbegrip van bepaalde Afrikaners geplaas soos hulle in die roman beoordeel word. Die vraag is in hoeverre die godsbegrip uitgewerk word on juis terreur te regverdig (Krecf 475,551 )? Die dood van die twee vroulike karakters word as 'n noodwendigheid verdra ter wille van die grotere boodskap van die regverdiging van revolusionère optrede en moontlik ook die regverdiging van terreur in breëre 
verband. Die tema van die onbarmhartige God as deel van die Afrikaner se beskouing oor God laat (bime die roman) ruimte vir die regverdiging van revolusionêre optrede. Hierdie sienswyse op sigself is natuurlik nie eties bedenklik nie, maar roep om diepere besimning.

Die politieke ryk word deur die hoofkarakter en sy twee vroulike medekarakters op revolusionêre wyse gesoek. Die roman eindig waar die politieke heil tog deurbreek. Die hoofkarakter word wonderbaarlik gered en hy self beleef die politieke vernuwing wat kom. 'in Nuwe politieke bestel word in die vooruitsig gestel en die verset teen die ou bestel was dus nie tevergeefs nie.

Die vraag ontstaan dus by die leser van die roman of dit 'in geregverdigde konklusie is - 'n konklusie waarmee die kerk wat deel was van die bestaande bestel rekening moet hou? Die vraag is immers of God as sodanig nie onregverdig is nie en die Bybel nie inderdaad 'n onregverdige God voorstel wat ook in die roman ontbloot word nie? Verder is die uraag of daar by die Afrikaners wat hulle wel op die Bybel beroep nie dalk werklik 'n godsbegrip bestaan wat uitermate bedenklik is nie?

\section{Die godsbegrip van die Ifrikaner}

\subsection{Die begrip}

Ten eerste moct duidelik aangetoon word daar slegs in afgeleide sin sprake is van die 'godsbegrip van die Afrikaner' aangesien daar selfs onder geloofsgenote van een kerk verskillende beskoumge aangaande God bestaan. In die benadering van die onderwerp sal daar tog na bepaalde tendense verwys moet word on te bepaal of die saak, wat deur die roman ter tafel gelê word, meriete het en sal die implikasies daarvan vir die godsbegrip van die Afrikaner oorweeg moet word.

\subsection{Tendense ten opsigte van die godshegrip van die. Afrikaner}

'n Bepaalde en tersaaklike tendens word deur die roman aan die orde gestel: die godsbegrip van 'n bepaalde Afrihaner (soos deur die roman self aangetoon) is gevorm deur sy beskouing aangaande die voorsienigheid van God. Daar kan egter ook aangetoon word dat die beskouing oor die voorsienigheid van God van groor belang is binne die denke van die Afrikaner. In dié verband is daar noue kontak gelè tussen die volk en die kerk, en is God se voorsienigheid dikwels ook as bewaring van die volk geinterpreteer In die verlede het ook die AfrikanerBroederbond 'n invloed uitgeoefen op die beskouing, sodat die godsbegrip bepaal is deur verskeic motiewe van volksafsondering en volkseiendomlikheid (Strauss, 1990:369). In aansluiting hiennee is daar ook dokumente wat die beskouing oor die voorsienigheid van God bevestig. Die dokument Ras. volk en nasie (1974) van die Nederduitse Gerefonneerde Kerk het hierdie sienswyse inderdaad pro- 
beer bevestig. Motiewe ten opsigte van die handhawing van afsonderlikheid, beginsels waarvolgens dit uitgewerk word en die metode om dit te bevestig, loop in die werk ineen, met die gevolg dat daar nie skerp onderskei word wat die Skrif leer nie (Strauss, 1991:442). Ook Jonker (1989a 153) dui aan dat die sogenaamde "volkstümliche Bindungen" vir die verstaan van die volk as Christelike gemeenskap van deurslaggewende belang was. Jonker meen dat die Afrikaner en die Nederduitse Gereformeerde kerk wel beinvloed is deur die beskouing dat die volk en kerk nou met mekaar geskakel moet word. Kinghorn (1985:9) dui aan dat ervaring vir die Afrikaner in die Nederduitse Gereformeerde Kerk beslissend was vir die verstaan van God: "Die kollektiewe ervaring verskyn nou as gefundeer in 'n universele ervaring wat op die universele skeppingswil van God berus". Daar is volgens Kinghom (1984:7) duidelike tendense om die begrip nas/e te oorspan. Verder dui hy aan dat 'n totaal nuwe hantering van die godsbegrip nodig is om die las wat apartheid daarop gelê het weg te neem (Kinghorn, 1990:21-36). Meiring (1975:59) meen dat nasionalisme en patriotisme dominant is in die Afrikaanse kerke. Die oortuiging van voorsienigheid in die lewe van die volk hang saam met die oortuiging dat God regeer en dat sy gesag afgewentel word op ander gesagsdraers (Van der Walt, 1989:3). Hierdie siening sou nie 'n korrekte beskouing wees nie, maar is tog bepalend vir die oortuigings en beskouings van die Afrikaner. Nicol (1990:51) meen in die verband dat die verhouding tussen heil en voorsienigheid belangrik is. Hierdie aspek is egter soms deur bepaalde Afrikaners misgekyk in hul interpretasie van die voorsienigheid van God.

Die hele apartheidsera word hiervolgens gekenmerk deur die oortuiging dat God alles beskik. Die teologiese tradısie waarop gebou word, is onseker, want alloewel Kuyper bygehaal word, is dit duidelik dat hierdie teologiese beskounge nie by loom geld nie (Smit, 1989:46).

Ten opsigte van bogenoemde aspek moet veral met Kmghom in gesprck getree word. Was hierdie oortuigings wel beslissend in die godsbegrip van die (bepaalde) Afrikaner? Dit kan moeilik ontken word dat die oortuiging van die beskikking en voorsienigheid van God wel beslissend meegespeel het. Kinghom (1986:193) se ontleding van apartheid en die Afrikaner se gebondenleid daaraan verdien ook aandag. Volgens die standpunt het die Afrikaner deur sy gereformeerde kerke 'n bepaalde godsbegrip gekonstrueer, waarin dit duidelik moes wees dat God apartheid bevestig (Kinghom, 1986:176-177). Hierdie godsbegrip is dan ontwikkel on bepaalde voorkeure te bevestig.

Kinghom toon aan dat besluite van vergaderinge en standpunte wat ingeneem is, duidelik gegrond is op die gedagte dat God afsonderlikheid handhaaf en dat Hy die God van afsonderlikheid is (Kinghom, 1986:175). Hiennee is dan gepoog om God so voor te stel asof Hy die afsonderlikheid in sy voorsienigheid vasgelê het (Kinghom, 1986:187). Dit kan nie ontken word nie dat die gedagte tog geleef het 
in die kerklike vergaderings wat oor apartheid besin het en dat dit ook die uitgangspunt onder bepaalde omstandighede was

Daar is wel die oortuiging dat God self die volk se roeping en taak bepaal: " $n$ Groot groep Afrikaners aanvaar 'n Christelike taak vir die Afrikaner in SuidAfrika. Hulle aanvaar dat die Afrikaner met 'n doel deur God hier geplaas is" (Fensham, 1984:15). Sou dit die noodwendige oortuiging wees vanuit die Calvinisme? (vgl. Van Niekerk, 1990:220). Ook Jonker (1989a: 157) skryf in die verband:

Ons Calvinistiese agtergrond is daarby vir ons 'n groot hulp, want die Calvinisme wil uiteindelik niks anders nie as dat elke duimbreedte van hierdie werklikheid onder die koningsheerskappy van Christus gestel moet word

Vanuit diè oottuiging kan geen volksmeerderwaardigheid afgelei word nie. Die Calvmisme laat immers geen volksmeerdenwaardigheid toe nie (Buys, 1987:8). Dit wil dus voorkom of daar wel apologeties aangetoon kan word dat ' $n$ gereformeerde beskouing aangaande God, soos dit voorgekom het by bepaalde Afrikaners, nie sonder meer 'n beskouing van 'n onderdrukkende God wat oordeel oor mense en wat net sy gunsgenote aanvaar, veronderstel nie. Alhoewel die begecte tot 'n eie land en selfregering deur teologiese paradignas ondersteun is en deur die Afrikaner vanuit die paradigmas beklemtoon is, kan daaruit nie afgelei word dat die Afrikaner 'n godsbegrip gevorn het van 'n eksklusiewe God wat onderdruk nie (Robbertze, 1991 833).

Ook Deist (1990:124 e.v.) gaan diepgaande op die saak in en formuleer bepaalde gevolgtrekkings. Hy is van mening dat die Afrikaner se burgerlike godsdiens sekere sake na vore gebring het (Deist, 1990:130). Die natuurlike orde van dinge soos dit sigself aanbied vir die naiewe ervaring het die basis gevorm vir teologiese refleksie (Deist, 1990:130). Dit was moontlik vanuit dié beskouing dat die algemene openbaring ook beslissend vir die teologiese denke is. Verder is gemeen dat die natuurlike orde van dinge beoordeel kan word en waargeneem kan word deur die sintuie en dat 'in duidelike beeld van God se wil daaruit gevorm kan word (Deist, 1990:131). Die Skrif, God se besondere openbaring, bevat verder onfeilbare inligting oor die oorsprong van die orde en doel van die natuurlike orde, verlig die insig in die natuurlike orde en maak dit waaneembaar, maar kan nie die algemene openbaring weerspreek nie (Deist, 1990:131). Die Sknf kan objcktief verstaan word deur middel van die eksegetiese ondersoek, waarin onder andere gesock word na die duidelike en letterlike betekenis van die geïnspireerde Woord van God 'Afrikaner-Calvinisme', waarin die objektiewe waarheid bevestig is, het gedien as die grond van die Afrikaner se oortuiging (Deist, 1990:131). Die Bybel moet dus gelees word soos hy homself aanbied. Die bevestiging dat die algemene openbaring ook 'n duidelike boodskap dra, is algemeen voorgehou (Deist, 1990:131). In die verband is 'n sirkelredenasie voltooi: 
We have now come full circle: an objective analysis of God's gencral revelation in the people's natural life, customs, beliefs and views leads us to a theory on God's will for society. The truth of this theory must be tested against scriptural teaching. But the truth about scriptural teaching is in the end measured by the history of the people, so that 'the people' becomes the ultimate judge on the correct exposition of God's revealed will in the Bible. (Deist, 1990:131.)

Deist is van mening dat vrees, die gevoel van onsekerheid, rassevoorkeur en ander sake eerder as die suiwer Woord, die burgerlike godsdiens bepaal het (Deist, 1990:135). Die vraag wat Deist dan aan die orde stel, is die vraag of geloof en religieuse oortuiging ooit vry kan wees van besoedeling deur die eie agtergrond en eie insig. Daarom kan dit wat tans as duidelike openbaring van God se woord voorgedra word ook in die toekoms sterk bevraagteken word (Deist, 1990:136). Deist koin tot 'n bepaalde gevolgtrekking:

Perhaps the horrible wrongs committed in the faith that Afrikaner civil religion was in perfect harmony with the will of God may serve as a warning against an all too easy identification of our religious beliefs and social actions with the will of God. (Deist, 1990:136.)

Dit moet duidelik wees dat daar deur bepaalde Afrikaners wel vanuit die oortuiging, soos geformuleer in sy burgerlike godsdiens, meerderwardig opgetree is en dat ook rassevoorkeur verkies is. Hierdie oortuiging het ongetwyfeld gelei tot groot onderdrukking en baie ellende. Dit bly egter 'n vraag of die Calvinistiese en die gerefonneerde interpretasie van die Skrif, soos ook deur baie Afrikaners voorgestaan, daarvan beskuldig moet word Was daar nie ook 'n eerlike soeke na God se Woord en sy wil vir 'n bepaalde situasie nie? Kan daar nie aangetoon word dat 'n bepaalde godsbegrip tog voorkom wat gegrond is op die Skrif wat God as goed beskou nie?

Dit is moontlik on die dokumente waarop bepaalde mense hulle godsdiens en godsbegrip fundeer te ontleed on te bepaal of strukturele geweld daarin bevestig word. In die Nederlandse Geloofsbelydenis word soos volg bely:

Ons glo almal met die hart en bely met die mond dat daar ' $n$ enige en enkelvoudige geestelike Wese is wat ons God noem Hy is ewig, onbegryplik, onsienlik, onveranderlik, oneindig, almagtıg, volkome wys, regverdig, goed en die alleroorvloedigste fontein van alles wat goed is.

Veral die begrip dat God die alleroorvloedigste fontein is van alles wat goed is, verdien aandag. Hierdie siening klop nie met 'n onbarmhartige beeld van God nie. Dit beteken egter nie dat die godsbegrip van die Afrikaner gegrond is op dic NGB nie, maar moontlik wel op 'n bepaalde verstaan van God soos Hy sou optree. Strukfurele geweld kan egter nie daanme regverdig word nie. Die feit dat in Brink se roman verwys word na Adam en Eva en die wyse waarop God 
sou optree deur hulle te veroordeel, dui op 'n bepaalde insig van die hoofkarakter wat nie bevestig word deur teologies interpretasie van die tersaaklike Skrifgedeelte nie (vgl. Vriezen, 1977:56, 182-190).

Dat strukture in stand gehou word in die oortuiging dat God daaroor waak, is wel 'n gereformeerde standpunt (vgl. Floor, 1974:20). Die wet is immers betekenisvol vir die hele lewe (Jonker, 1989b:297-298; Douma, 1984:64 e.v.). Deur middel van die antitese word die onderskeid tussen Christen en heiden bevestig in die strukture wat God daarstel (Velema, 1979:17-24). Dit beteken egter nie dat die strukture gewelddadig mag wees nie en al sou dit die godsbegrip van bepaalde Alrikaners wees, sou dit nie die bepaalde gerefonneerde standpunte weerspieel nie. Dit is van die allergrootste belang dat God heil wil voortbring vir die mens op aarde en dat sy beloftes aan alle mense gemaak word. Hiervolgens is Hy geen urede tiran wat sy ryk ten alle koste in stand moet hou nie. Die vraag kan egter wel gestel word of die godsbegrip van die gerefonneerde Afrikaner nie wel so 'n God voorhou nie - 'n siening van God wat dui op onbannhartigheid en wrede vervolgsug, 'n God wat mense uitverkies en ander verdoem. Het apartheid en die regverdiging daarvan geslaag daarin on 'n godsbeeld voor te hou waarin God inderdaad onbarmhartig en diktatoriaal voorgehou word?

Die vraag na die betekenis en waarde van die uitverkiesing word hiennee aan die orde gestel. Jonker $(1988: 13,14)$ hanteer die saak volledig en skryf in die verband dat die uitverkiesing in die Bybel steeds beskou word as iets waaroor gejuig word en waarvoor God gedank en ook geeer moet word. Die uitverkiesing is geensins te verstaan as willekeurige beslissinge van God, waarin die mens uitgeskakel word en ook op willekeurige wyse uitgelewer word aan die voorkeure van God nie Buys skryf in die verband (1987:8):

Faith in our unconditional election will always humble us and prevent us from thinking that our racial background in any way makes us more accep. table to God

Die vraag is egter of die oonuiging nie deur bepaalde Afrikaners as die bevesliging van sy roeping en meerderwaardigheid beskou word nie en ook as bevestiging van die feit dat God sy bestel ten alle koste in stand hou Indien geoordeel word vanuit die praktiese omstandighede, is dit duidelik dat daar wel sodanige aanduidings bestaan. Dit is egter ook moontlik om aan te dui dat, vanuit in bepaalde gereformeerde beskouing ran die Bybel, oor God gepraat kan word in terme van sy barmhartigheid God is juis die barmhartige in sy seun Jesus Christus. Hy wil geken word as die God van genade en liefde (Joh. 3:16, I Joh 4:7-12;2 Kor $5: 11-21, \mathrm{Kol}, 1: 15-20)$. Mense kan Hom egter verkeerd ken en selfs 'n verkeerde begrip oor Hom vorm. 


\subsection{God se optrede in die wêreld}

Vervolgens word die beskuldiging van die hoofkarakter in die roman dat die Bybel self 'n God veronderstel wat onderdruk en oordeel en strukturele geweld in orde hou, bespreek. Daar bestaan min twyfel dat God wel in die Ou Testament beskryf word as heilig, regverdig en een wat die kwaad nie verdra nie. Belangrik is ook die talion-begrip wat voorkom: daarvolgens word dit baie duidelik dat God eis wat Hy as reg beskou en daarom ook 'n tand vir 'n tand en lewe vir lewe opeis. Vanuit hierdie begrip kan dit duidelik wees dat God wel deur middel van die strukture wat Hy daarstel sy ryk in stand hou en opeis wat syne is. Hierdie begrip moet teen die agtergrond van die Ou-Testamentiese wêreld oorweeg word. Eckart Otto (1990:510-512) het breedvoerig aandag gegee aan die probleem. Volgens sy oortuiging sluit die regsorde waarin God optree ten nouste aan by die regsorde van die Oud-Nabye Ooste (Otto, 1991:159). God se handelinge in die Ou Testament moet teen dié agtergrond beskou word (Otto, 1988.79) ondat 'n brug vanuit die Ou-Testamentiese wèreld na die prinitiewe samelewing geslaan kan word. Juis daarom is daar, volgens die Oud-Nabye Oosterse reg, duidelike tekens van oordeel in die Ou Testament (Otto, 1976:52). Sou dic gevaar om 'n godsbegrip reglynig uit die Ou Testannent af te lei daartoe lei dat God as onbarmhartig beskou word? Sou die hele kulturele wêreld waarin God optree volgens die talion-begrip eers verreken moet word? Tree God dan so op binne die ruimte van die oud-Hebreeuse bestaan waar 'n totaal ander beskouing teenoor geweld geld? Verskillende moontlikhede bestaan wanneer die probleem van geweld van nader beskou word. God is die een wat sy ese orde stel en die reg het om te eis dat die orde in stand gehou word. Helberg (1989:10) meen dat die Ou Testament eintlik die mislukking van die mens en van die verbondsvolk as tema het. Juis daarom is God egter steeds die genadige, Hy begin 'n nuwe verbond met die mens.

Daar is Ou-Testamentici wat meen dat geweld inderdaad afgewys word - ook in die Ou-Testamentiese wèreld - ell dat die talion-begrip nie op God van toepassing gemaak kan word nie. In dié verband word dan verwys na die optrede van God as regverdige en die een wat heil en verlossing meebring. Hy bring heil en verlossing, en geweld word deur Hom veroordeel (Snyman, 1992:6-8, 12). Dit mag dus wees dat die gepostuleerde godsbegrip in Brink se roman juis wil aantoon dat Afrikaners op dié wyse 'n godsbegrip kon vonn - 'n godsbegrip wat berus op oortuiginge wat op 'n bepaalde wyse uit die Ou Testament afgelei word. Op apologetiese wyse kan die beskuldiging teen die God van dic Bybel, soos deur die hoofkarakter belig, teëgespreek word in die lig van die bannhartigheid van God wat duidelik in die Ou Testament voorkom 


\section{Slot}

Die godsbegrip van die Afrikaner kan moeilik empiries ontleed en vasgestel word. Tog kan aangetoon word dat bepaalde elemente teenwoordig was in die burgerlike godsdiens van die Afrikaner (Deist, 1990:136). Brink se hoofkarakter is dus moontlik eensydig in sy oordeel, maar die oordeel open die deur vir verdere debat. Ook die implisiete outeur se oordeel is moontlik eensydig, maar skets immiddels ook 'n werklikheid wat wel bestaan en waaraan aandag gegee moet word. Dit neem nie weg dat die kritiek, soos in die roman geïmpliseer, ook 'n beslissende rol speel in die regverdiging van revolusionêre optrede en terreur nie Terreur is nie geweld teen 'n owerheid nie, maar ondiskriminerende doodmaak om politieke mag te bekom (vgl. Thielicke, 1965:237 e.v.; Heyns, 1989:191 e.v.). Dit is moontlik dat die implisiete outeur tog die leser wil oortuig dat onder bepaalde onderdrukkende omstandighede, waarin 'n bepaalde bestel selfs misbruik van hulle verhouding tot God maak, terreur geregverdig is. Geweld en die regverdiging daarvan is eties gesproke uiters gekompliseerd. Daar bestaan geen maklike oplossing vir die probleem om geweld te regverdig nie, maar juis daarom is 'n vereenvoudiging van die probleem op sigself problematies. Ook die roman ontkom nie aan die gevaar nie.

Die ondersoek na die godsbegrip in Brink se roman toon duidelike tendense wat inderdaad dui op die gevaar om jou op God te beroep vir die strukturele geweld wat jy pleeg. Die gevaar bestaan egter ook dat die godsbegrip van 'n bepaalde groep gebruik word om terreur teen die mense wat in God sou glo te regverdig.

\section{Bibliografie}

BRINK, A P 1991 Die kreef raak gewoond daaraan Kaapstad Human en Rousseau BUYS, P J 1987. Calvinism Does not Teach Apartheid. Potchefstroom: PL vir CHO (Instituut vir Reformatoriese Studie Studiestuk no 122, Mei)

DEIST, FE 1990 Notes on the Context and Hermeneutics of Afrikaner Civil Religion Missiomalia, 18(1):124-139. April.

DIE NEDERLANDSE GELOOFSBELY'DENIS ( $/$ I : Glo en Bely 1989. Leerboek vir katkisante Bloemfontein NG Kerk-Jeugboekhandel p 230.)

DOUMA, J 1984 Verantwoord handelen Ethische bezinning Kampen : Van den Berg

FENSHAM, FC. 1984 Die Christen-Afrikaner in beweging in die twintigste eeu Potchefstroom PU vir CHO (Instituut vir Reformatoriese Studie Studiestuk no 202, Oktober.)

FLOOR, L 1974 Reformasie versus revolusie: 'n prinsipiele orientering (ln Smit, E J e a Reformasie en revolusie. Potchefstroom PU vir CHO p 11-22.)

HELBBERG, J I. 1989. Hoe benader en hanteer die Christenprediker die Ou Testament? In die Skriflgr, 23(89) 5-19, Maart

HFYNS, J A 1989 Teologiese etick. Deel 2/2 Sosiale Etiek Pretoria NG Kerkboekhandel

JONKER, W D 1988 Uit vrye guns alleen - oor uitverkiesing en verbond. Pretoria NG Kerkboekhande] 
JONKER, W.D 1989a Suid-Afrika se verbondenheid met Europa Die teologie Tydskrif vir Geestesw'elenskappe, 29(2):146-157, Junie

JONKER, W D 1989b. Die eie aard van die gereformeerde spiritualiteit Nederdritse Gereformeerde Teologiese 7jdskrif. 30(3) 288-299, Julie

KINGHORN, J. 1984 Theology of Exploitation? Jomrthl of Theology for Southern Africa. 84:4-13, Des

KINGHORN, J. 1985. Apartheidsteologie binne die NGK: enkele teologiehistoriese opmerkings Tydskrif ir Geesteswetenskappe, 25(1):1-13, Maart

KINGHORN, J 1986 'n Evaluasie van apartheidsteologie (In Kinghorn, J red. Die N G Kerk en apartheid. Johannesburg : Macmillan p. 167-193.)

KINGHORN, J. 1990. On the Theology of Church and Society in the DRC .Journal of Theology for Sow hern Africa, 70:21-36, March

MEIRING, P.J. 1975. Nationalism in the Dutch Reformed Churches (In Sundermeier, T Church and Nationalism in South Africa. Kaapstad Ravan. p 56-66.)

NICOL, W 1990 God in stryd teen apartheid: 'n Teologiese gesprek met Albert Nolan oor sy "God in South Africa". Sirriptura, 33:44-54, Mei

OTTO, E. 1976 Erwagungen zum überlieferungsgeschictlichen Ursprung und "Sitz im Leben" des jawistischen Plagenzyklus lélus Tesłamentum, 26:3-27, Januarie

OTTO, E 1988 "Wir wollen den Wald und Fürchten dennoch seine Geister" Beobachtungen zur Rezeption des Alten Testaments in Melanesien. Zeilschrift firr Mission, 14(2): 70-82.

OTTO, E. 1990 Wandel der Rechtsbegrindungen in der Gesellschafisgeschichte des antiken Israel: Eine Rechtsgeschichte des "Bundesbuches" Ex 20:22-23:13. Resensie deur Dozeman, Thomas, Journal of Biblical literalure', 109:510-512

OTTO, E 1991. Die Bedeutung der altorientarischen Rechtsgeschichte für das Verstandnis des Alten Testaments Zeilschrift fir Theologle und Kirche. 88(2) 139-168

Ras, volk en nasie en volkereverhoudinge in die lig van die Skrif. 1974 Goedgekeur en aanvaar deur die Algemene Sinode van die Nederduitse Gereformeerde Kerk Oktober Kaapstad NG Kerkuitgewers

ROBBERTZE, HCG 1991. Theological Paradigms and Conservative Afrikaners Hervormde Teologiese Sundies, 47(3) 825-835, Sept

SMIT, J.H 1989 Abraham Kuyper en volksideologie onder die Afrikaners In die Skriffig. 23(91):45-55, Sept

SNYMAN, S D 1992 Geweld, die Ou Testament en 'n Nuwe Suid-Afrika Bloemfontein UOVS

STRAUSS, P J 1990 Die Afrikaner-Broederbond se beweerde beinvloeding van die Nederduitse Gereformeerde Kerk in sy optrede teen die Christelike Instituut Noderdurtse Gereformeerde Teologiese Tydskrif. 31(3).357-370

STRAUSS, P J 1991. Beginsel of metode? Die Nederduitse Gereformeerde Kerk en apartheid na Cottesloe Nederdinitse (iereformeerde Teologiese Tydskrif. 32(3):436-446

THIELICKE, H 1965 Theologische Ethik 11/1 Tubingen Mohr

VAN DER WALT, B J 1989. Owerheid en onderdaan in Suid-Afrika Potchefstroom PU vir CHO (Instituut vir Reformatoriese Studie Reeks F No 257, Mei.)

VAN NIEKERK, A S 1990 Nog nadenke na aanleiding van 'nadenke van 'n Afrikaner' deur H J C Pieterse Hervormule Teologiese Simdies, 46(1 \& 2) 207-221, Jun

VELEMA, WH 1979 Midden in de maatschappij: Over ethiek en samenleving. Kampen Kok

VRJEZEN, Th C 1977. Hoofdlijnen der Theologie van het Oude Testament. Wageningen Veenman 